\title{
A perspective on corrosion of multi-principal element alloys
}

\author{
N. Birbilis ${ }^{1,5 凶}$, S. Choudhary $\mathbb{D}^{2,5 凶}$, J. R. Scully $\mathbb{D}^{3,5}$ and M. L. Taheri $\mathbb{D}^{4,5}$
}

Metallic alloys are critical to essentially all advanced technologies and engineered systems. The well-documented impact of corrosion (and oxidation) of alloys, remains a significant industrial and economic challenge, year on year. Recent activity in the field of metallurgy has revealed a class of metallic alloys, termed multi principal element alloys (MPEAs) that present unique physical properties. Such MPEAs have in many instances also demonstrated a high resistance to corrosion - which may permit the broader use of MPEAs as corrosion resistant alloys (CRAs) in harsh environments. Herein, the progress in MPEA research to date, along with prospects and challenges, are concisely reviewed-with potential future lines of research elaborated.

npj Materials Degradation (2021)5:14; https://doi.org/10.1038/s41529-021-00163-8

\section{INTRODUCTION}

Emerging technologies often place critical demands upon the portfolio of existing materials, namely metallic alloys, such that material development remains necessary. Such emerging technologies include: energy (e.g., materials for solar thermal ${ }^{1,2}$, materials for high temperature process, materials for nuclear technologies ${ }^{3}$ ); Transport (e.g., materials for propulsion systems, gas turbines and elevated temperature use ${ }^{4,5}$, materials for marine applications, lightweight vehicles); new technologies (e.g., smartphones, consumer products, and even spacecraft); biomedical technologies, and the ongoing need for engineering materials that are more durable and sustainable. In the context of all the aforementioned applications, corrosion and oxidation often remain key factors that limit many technologies. This is perhaps unsurprising from the perspective that metallic alloys are inorganic materials with a tendency to return to their original form (most likely an oxide rich ore)-however, there may be hope.

In recent years, the performance of a class of metallic materials known as high entropy alloys (HEAs) has very rapidly captured the attention of researchers, the world over. The concept of HEAs was reported by Yeh et al. ${ }^{6}$, who described that by blending five metallic elements together (or possibly, more than five elements) in approximately equiatomic proportions, then the attendant entropy of mixing was high; resulting in a nominally single-phase alloy being produced. Empirical rules for the design of HEAs that adopted the pursuit of a high entropy of mixing were developed $^{7,8}$ and examples of HEAs include CoCrFeNiMn ${ }^{9}$, TaNbHfZrTi ${ }^{10}$, and $\mathrm{Al}_{20} \mathrm{Li}_{20} \mathrm{Mg}_{10} \mathrm{Sc}_{20} \mathrm{Ti}_{30}{ }^{11}$. What was perhaps one of the most remarkable empirical findings in the recent history of metallurgy, is the physical properties of HEAs, as reported in the detailed review by Zhang et al. ${ }^{12}$; revealing that HEAs have very high strength and excellent thermal stability, placing them in their own unique (and favourable) window of so-called 'propertyspace $^{\prime 13}$. This new property space has to date focused mainly on mechanical properties, with corrosion and oxidation resistance relatively less explored. The purpose of this perspective is to provide a concise synopsis of the field from the perspective of corrosion and oxidation, specifically, what is presently known, what is not known, where challenges and opportunities reside.
Researchers have taken great interest in the topic of HEAs, many seeking to produce their own alloys, with variations to the original 'recipe' or formulation criteria for HEAs emerging. For example, if calculating the entropy of mixing for a particular combination of elements, it is possible to achieve a high entropy of mixing with say, only four elements in near equiatomic proportions (as opposed to five+ elements), whilst it is also possible to maintain a high entropy of mixing with minor alloying additions in the case of one or more elements, as well ${ }^{14}$. To this end, a more broad definition of HEAs that has been termed as CCAs (compositionally complex alloys or complex concentrated alloys) has emerged ${ }^{15}$. Examples of alloys termed CCAs include AlTiCrV ${ }^{16}, \mathrm{Al}_{0,3} \mathrm{CoFeNi}^{17}$ and $\mathrm{NbTiZrCr}^{18}$.

In fact, more broadly, it has been found that the unique properties displayed from HEAs and CCAs, may also be possible to achieve in alloy systems where there are only two or three socalled 'principal' alloying elements. Example of such multi-principal element alloys (MPEAs) include $\mathrm{Ni}_{40} \mathrm{Co}_{40} \mathrm{Ru}_{20}{ }^{19}$, FeCoNiCr 0.5 and $\mathrm{Ni}_{38} \mathrm{Fe}_{20} \mathrm{Cr}_{22} \mathrm{Mn}_{10} \mathrm{Co}_{10}{ }^{21}$. The compositional possibilities for MPEAs are much broader, as multiple trace or functional elements may be utilised, and adaptations of more well-understood systems (such as nickel alloys and the family of so-called corrosion-resistant alloys, CRAs) can be expanded ${ }^{22}$. It is none-the-less emphasised that such MPEAs are indeed unique to any alloy systems previously explored. To make the distinction of these so-called 'new' alloy systems clear, a schematic is presented (Fig. 1), revealing the broad concepts of such alloy systemsnoting that the definitions are not rigid and regularly evolving in the field. From herein, the term MPEA will be utilised to describe and encompass all of MPEAs, CCAs and HEAs.

A synopsis of the open literature (as determined by data from Web of Science ${ }^{T M}$ (Clarivate analytics) between 1999 and August 2020) reveals that the number of publications - when using the expanded form of the search terms HEA, CCA and MPEA-is rapidly increasing. An analysis of studies in the categories of MATERIALS SCIENCE MULTIDISCIPLINARY and METALLURGY METALLURGICAL ENGINEERING, reveals the increase in the number of publications is presented in Fig. 2 - which shows under 50 publications per year until 2013 , after which a significant non-linear increase has occurred to >450 in 2019.

${ }^{1}$ College of Engineering and Computer Science, Australian National University, Acton, ACT, Australia. ${ }^{2}$ Department of Materials Science and Engineering, Monash University, Clayton, VIC, Australia. ${ }^{3}$ Department of Materials Science and Engineering, University of Virginia, Charlottesville, VA, USA. ${ }^{4}$ Department of Materials Science and Engineering, Johns Hopkins University, Baltimore, MD, USA. ${ }^{5}$ These authors contributed equally: N. Birbilis, S. Choudhary, J.R. Scully, M.L. Taheri. ${ }^{凶}$ email: nick.birbilis@anu.edu.au; sanjay. choudhary@monash.edu 


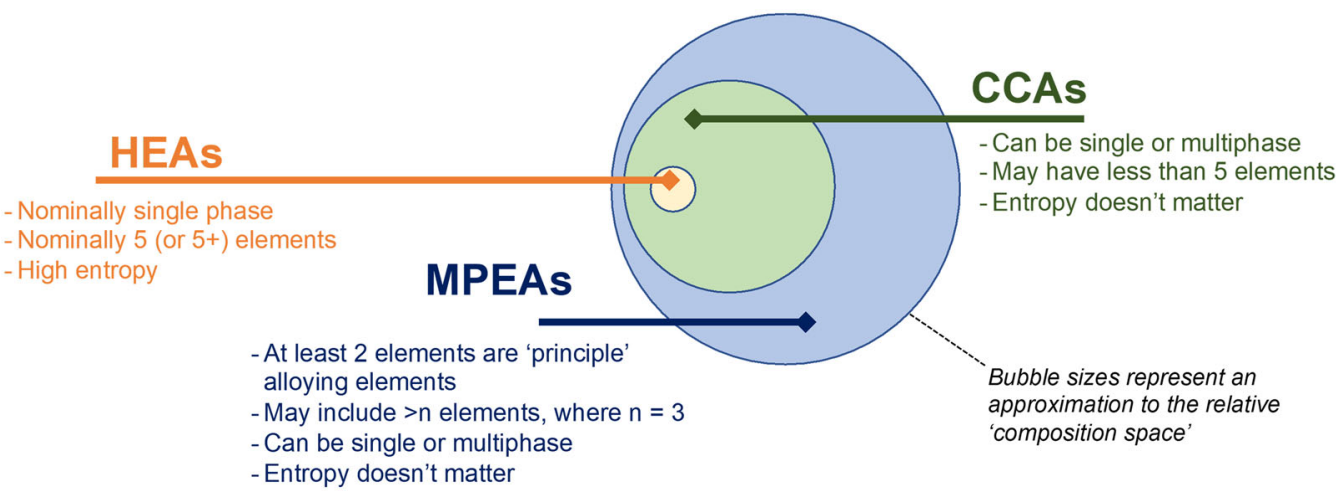

Fig. 1 A schematic representation of the classification notions for multi-principal element alloys (MPEAs). HEAs may be considered as a subset of CCAs; which in turn may also be considered a subset of the broader description of MPEAs-whereby the terminology of MPEAs encompasses a broad range of new and emerging metallic alloys.

Figure 2 also indicates the key funding sources supporting research in the field.

In order to assess the origins of such publications, along with the respective nations contributing to the field, the respective institutions in those nations, and the most productive authors in the field, further analysis was carried out. The compilation in Fig. 3 indicates that the greatest output in publications in the field of HEAs, CCAs and MPEAs, is China, followed by the USA. The combination of China and the USA accounts for $\sim 72 \%$ of all publications in the field since 1999. The contributing European nations at some scale, were Germany and France, with the remainder of the nations being in Asia (whilst the other category includes the rest of the world). This breakdown of research by nation is revealing, as it demonstrates the so-called early adopters of $R \& D$ in the field, and where the respective expertise resides. Of the contributing institutions, the largest number of publications have come from the University of Tennessee, where the most productive researcher (P.K. Liaw) is based. To supplement the information in Fig. 3, the inset of Fig. 2 provides the source of funding for the research publications, which reveals the largest single funding source (affiliated with publications, not a financial amount) is the National Natural Science Foundation of China.

\section{WHAT DO WE KNOW?}

A review of the mechanical performance of alloys within the MPEA classification has been assembled ${ }^{12,23}$. Whilst the mechanical properties of a selection of MPEAs appear to be 'excellent' (typified by yield strengths in excess of $1 \mathrm{GPa}$ ), mechanical performance remains variable depending on the alloy microstructure. The key aspects of microstructure that are critical are the type of matrix phase (e.g., an FCC matrix is associated with demonstrations of the highest ductility, whilst BCC and ordered BCC alloys have revealed lower ductility). The presence of many unique phases has also been revealed ${ }^{24-28}$ in the case of MPEAs, with many phases having been observed for the first time and are genuinely new discoveries. The complexity of microstructures, often with very high volume fractions of a second phase ${ }^{29}$, may also limit the ductility of MPEAs.

In addition, the so-called 'energetic landscape' of MPEAs is such that there exists a propensity for order-induced fluctuations to influence stacking fault energy and Peierls stress ${ }^{30-33}$. These fluctuations present an opportunity to tune alloys for desired mechanical properties based on order and resulting energy distributions.

The majority of empirical studies to date reveal that MPEAs are generally thermally stable-meaning that they retain their room temperature microstructure and properties to elevated temperate (akin to 'superalloys') ${ }^{34-37}$. However, MPEAs being universally thermally stable is a generalisation with notable exceptions ${ }^{7}$, this revelation also highlights a vast requirement of future work, covered below.

The aqueous corrosion of MPEAs has been studied with some purpose in the past 5 years, with very few reports prior to 2015. This is in spite of a report as early as 2005 by Yeh and co-workers, who indicated that HEAs present superior aqueous corrosion resistance than 304 stainless steel ${ }^{38}$. A synopsis of the corrosion characteristics of HEAs was published by Qiu et al. in $2015^{39}$, who made the generalised observation that HEAs and CCAs were inherently corrosion resistant. More specifically, the revelation that alloys with highly heterogeneous microstructure were found to be corrosion resistant was counter to conventional wisdom. Such work was followed up with a further broad survey of the corrosion of high entropy alloys, published in this journal ${ }^{40}$ and in a review by Shi et al. ${ }^{41}$ and Scully et al. ${ }^{42}$ highlighting that significant further work was warranted in the field, in order to rationalise the mechanistic aspects of the corrosion resistance of MPEAs.

Specifically, a wide variety of oxides are reported both during aqueous corrosion and high temperature oxidation studies based experimental enquiry. All stages of corrosion merit investigation but the role of the oxide in mediating uniform corrosion is one of the first topics to consider. The equilibrium thermodynamic assessments that underpin both the notions of classical passivity of metals (i.e., Pourbaix Diagrams) have just recently been extended to consider the stability of solid solution oxide compositions based on various host oxide lattice structures such as corundum. It is found for a non-equiatomic $\mathrm{Ni}-\mathrm{Cr}-\mathrm{Ni}-\mathrm{Fe}-\mathrm{Mn}$ alloy that a corundum solid solution containing $\mathrm{Cr}$ and Fe but not $\mathrm{Mn}$ is the most stable oxide formed at $\mathrm{pH} 4$ in $\mathrm{NaCl}$ in agreement with experiment ${ }^{21}$. This is an advancement but there remains an open question regarding whether equilibrium thermodynamics, particularly of single element and spinel stoichiometric oxides, are even relevant? Likely, solid solutions must be considered, but the thermodynamic probability of forming various combinations of single elements oxides ${ }^{43}$ as well as what factors change the prevalence of forming a particular oxide should be considered. Moreover, so-called 'third element effects' as seen in certain FeCrAl alloys should be considered. These undertakings at minimum are likely necessary in order for thermodynamics to remain relevant.

Some of the most cited works on the corrosion of HEAs include the work of Shi et al. ${ }^{44}$ who studied the $\mathrm{Al}_{\mathrm{x}} \mathrm{CoCrFeNi}$ system with varying Al-content, and the work of Luo et al. ${ }^{45}$ who studied the CoCrFeMnNi relative to stainless steel in sulfuric acid. Both studies, along with several others more broadly ${ }^{46-50}$ note the corrosion resistance of the respective alloys, and allude to mechanistic aspects. However, what has remained clear is that detailed surface analysis has been lacking in the field to date, 


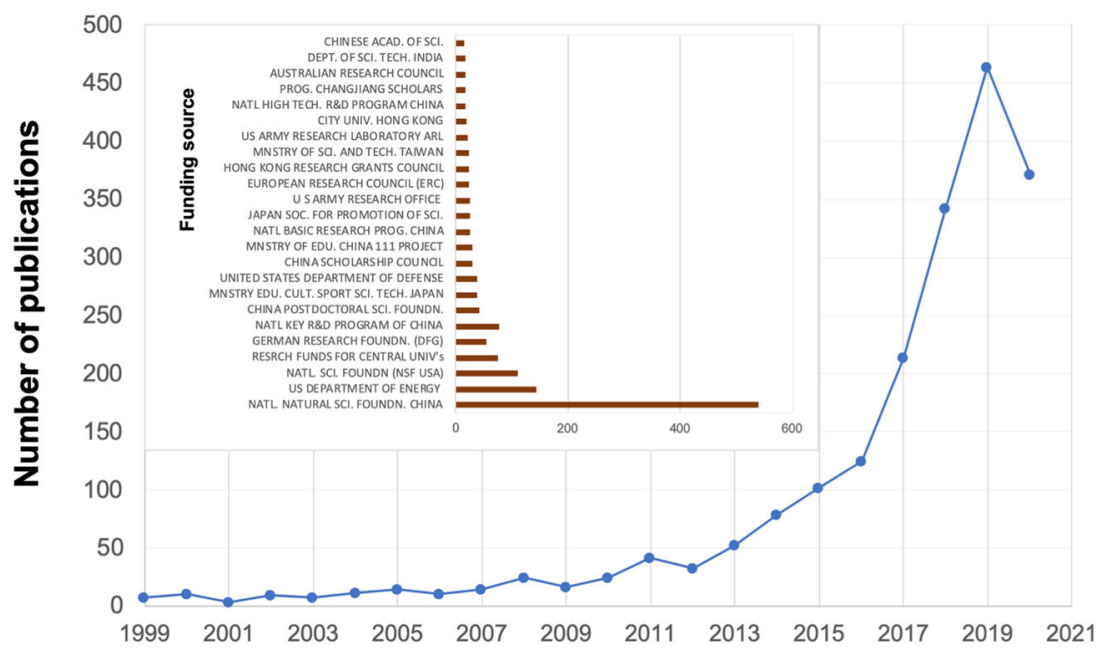

Fig. 2 Number of unique archival publications in the field of HEAs, CCAs and MPEAs as determined from Web of Science ${ }^{\text {TM }}$ for the period of 1999 to August 2020. The inset indicates the associated funding source attributed to the respective publications.

and is an aspect that has been sought to be clarified in a number of emerging studies. To date information is vague and oxides during dry high-temperature oxidation and aqueous corrosion are often characterised as complex suggesting a variety of compositions and phases. Understanding of these oxides is important given that they likely regulate thick film oxidation and thin-film high-field passive current densities which are observed to vary by orders of magnitude depending on MPEA composition $^{51}$. For example, XPS has been sparsely applied to the study of HEAs. Of the studies that have applied XPS, this has occurred on systems, including TaNbHfZrTi ${ }^{46}, \mathrm{CoCrFeNiMn}{ }^{52}$, and $\mathrm{Al}_{\mathrm{x}} \mathrm{CoCr}$ $\mathrm{FeNi}^{53}$. The key findings from XPS studies to date have highlighted that surface oxides upon MPEAs are highly complex, and are comprised of various oxide species that present as a non-stoichiometric combination of the constituent alloying elements often situated on a host oxide lattice structure such as corundum. These oxides may also be formed by solute capture (i.e., kinetic factors ${ }^{54}$ ) but in some cases may be favoured based on thermodynamics when solid solutions are found to form stable oxides with the most negative formation energies. The benefit from 3-D atom probe tomography and transmission electron microscopy has been useful to help confirm whether oxides consist of distinct phases separated stoichiometric or non-stoichiometric forms or solid solutions. Recent research has identified that both kinetics and thermodynamics are not mutually exclusive in the case of secondary phase evolution ${ }^{28}$ and oxide evolution ${ }^{55}$ in MPEAs.

It is clear that a variety of techniques must be applied to determine the fate of elements and character of the oxide during oxidation. Oxide structure, as well as composition, must both be understood. XPS is insufficient to determine molecular identities of oxides ${ }^{56}$-despite popular misconceptions-because the binding energies of core-level electrons may differ only slightly for various oxides ${ }^{57,58}$. As such, a combination of methods will be required to unambiguously determine the nature of the oxides. Most recently, the utility of a method known as atomic emission spectroelectrochemistry (AESEC) has been applied to the study of MPEAs ${ }^{59-61}$. This method, which is an in-line spectroscopy method that couples an electrochemical cell to an inductively coupled mass or optical emission spectrometer ${ }^{62,63}$ permits a timeresolved analysis of dissolution products with high resolution. These studies have been able to unambiguously clarify that the dissolution (or reaction) of MPEAs with their environment is 'incongruent', and non-stoichiometric ${ }^{21,59-61}$. This characteristic is not unique to MPEAs per se, but is unique on the basis that the extent of incongruent dissolution is influenced by the bulk alloy compositions having multiple principal elements, and that the surface oxide composition (and near-surface alloy composition) is in a continuously, kinetically, evolving state. This feature of MPEAs, is a key aspect of their corrosion performance that rather than being problematic, is most relevant to their high levels of corrosion resistance. This level of complexity will also be critical to emerging models for the rationalisation and subsequent design of MPEAs ${ }^{64}$.

Another unique aspect of MPEAs is their electrochemical performance more generally. Recent work has highlighted that HEAs (namely, $\mathrm{Ni}_{20} \mathrm{Fe}_{20} \mathrm{Mo}_{10} \mathrm{Co}_{35} \mathrm{Cr}_{15}$ ) may be a highly active and stable electrocatalyst for hydrogen evolution reaction ${ }^{65}$. This is noteworthy in that there is no noble metal element with the optimal adsorption energy or filled $4 \mathrm{~d}$ electron shell, as in the case of Ru additions ${ }^{55,60}$.

Whilst research related to the corrosion of MPEAs remains nascent, research related to the high-temperature oxidation (at temperatures $» 1000^{\circ} \mathrm{C}$ ) of MPEAs is equally nascent. This statement is however qualified on the basis that there are so many emerging variants of MPEAs, that a comprehensive treatise of the field is already untenable, and works that make significant insight into specific systems are most relevant. There are however, already several seminal papers in the field of oxidation of MPEAs ${ }^{66,67}$, including works that have focused on so-called refractory HEAs inclusive of the following alloy families $\mathrm{TaMoCr}$ TiAl, NbMoCrTiAl, NbMoCrAl, TaMoCrAl, NbMoTaW, VNbMoTaW, TaNbHfZrTi and CoMoVW ${ }^{68-73}$.

In terms of rationalising oxidation of MPEAs, Butler and Weaver $^{67}$ noted that AlCoCrFeNi alloys exhibited a parabolic oxide growth similar to $\mathrm{NiCrAl}$ alloys-also indicating that oxidation was influenced by the relative $\mathrm{Al}$ concentrations (whereby an increased $\mathrm{Al}$ content improved the continuity and internal location of the $\mathrm{Al}_{2} \mathrm{O}_{3}$ scale). In a comprehensive study by Dabrowa and co-workers ${ }^{74}$, who studied the effect of $\mathrm{Cu}$ content on oxidation of $\mathrm{AlCoCrCu} F \mathrm{FeNi}$, they also noted parabolic constants. As such, there remains significant further work required in the field of MPEA oxidation ${ }^{75}$.

These studies highlight the presence of a complex and dynamic diffusion process associated with MPEA oxidation. The vast compositional space offers the opportunity to tailor these processes toward improved protection. On a related note, the wear and fatigue properties of MPEAs are not covered in detail in this concise perspective. However, pertinent references (including a recent review) are provided ${ }^{76-82}$. 


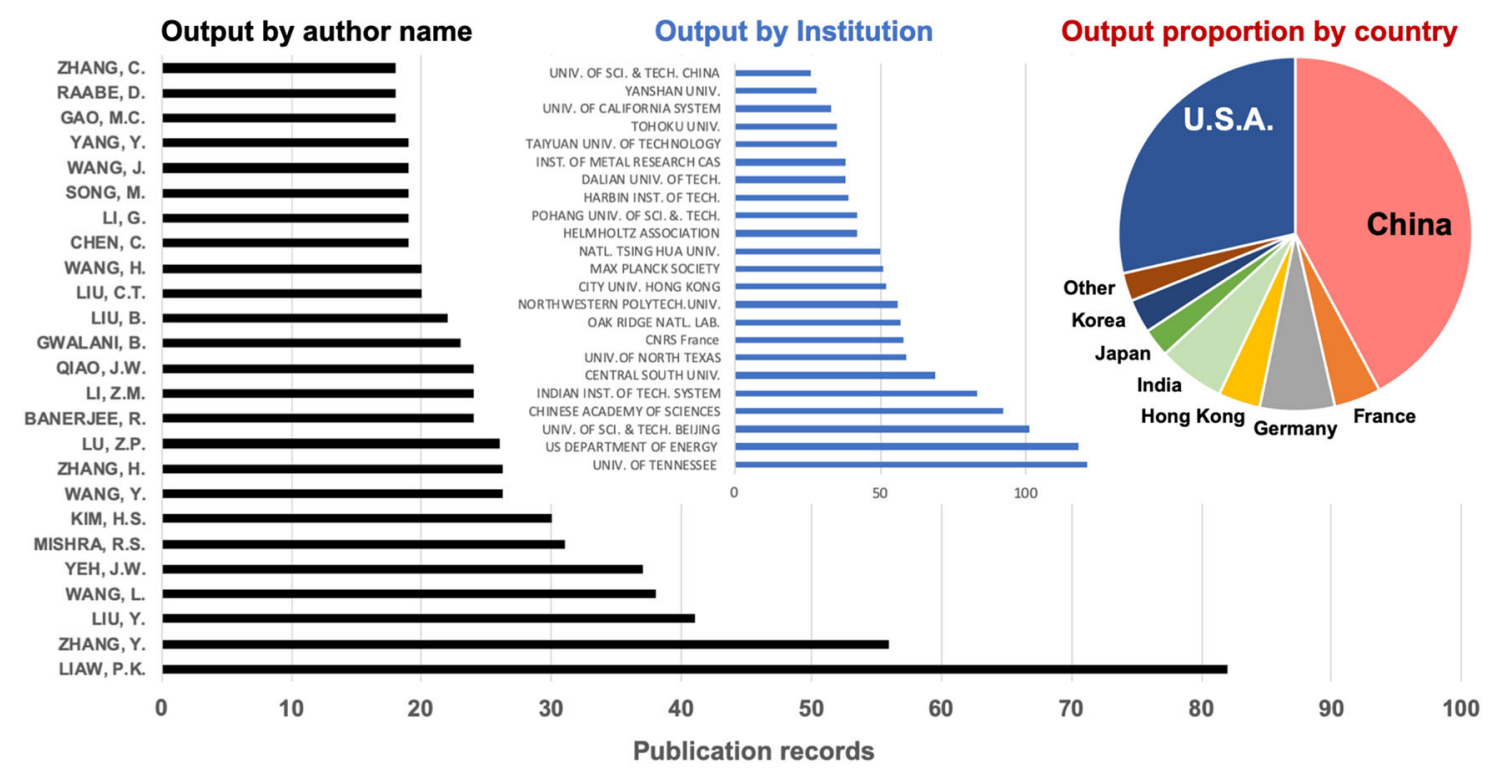

Fig. 3 A schematic representation of the publication outputs in the field of HEAs, CCAs and MPEAs as determined from Web of Science ${ }^{T M}$ for the period of 1999 to August 2020. The representation is limited to the 25 most published authors, and the 23 most published institutions. The publication proportion by country is an aggregate of the field over the 21-year period.

\section{WHAT REMAINS UNKNOWN?}

The production of MPEAs may be accomplished by various methods, however arc-melting in controlled environments remains the most common production route for ingots of appropriate scale (although spark plasma sintering ${ }^{83}$, and additive manufacturing ${ }^{84}$ have all been reported to date). As a consequence, the majority of MPEAs (and most certainly, HEAs within that category) are studied in their 'as cast' form. This is not an issue per se, as many engineering alloys used in their 'as produced' form, however it also emphasises two key aspects that are critical to a lack of more general understanding in MPEAs. These aspects are (i) the phase diagrams associated with most MPEAs studied to date, are unknown, and are difficult to calculate. This means that temperatures where phase changes may occur, and even melting temperatures of many MPEAs studied widely, are largely unknown. This aspect is being addressed somewhat more generally by the inclusion of MPEAs in common CALPHAD software (such as Pandat ${ }^{\mathrm{TM}}$ and Thermo-Calc ${ }^{\mathrm{TM}}$ ) in recent iterations of their software-however empirical evidence for validations remains scarce. (ii) Essentially all (or the vast majority) of studies to date on MPEAs do not study microstructural variations of the same alloy. This aspect is not the case for the traditional study of structural alloys, which have been broadly studied as a function of thermomechanical processing. Again, this points to a core lack of understanding in the thermomechanical processing of MPEAs. The upside of such a lack of understanding is perhaps, that there is scope for the (favourable) properties measured to date, to be further optimised. There are examples of several age-hardenable HEAs already published $^{85-88}$, revealing that even the ( $\mathrm{fcc}$ ) FeCoNiCr system has remarkable strength and high ductility when modified with minor additions of $\mathrm{Al}$ and Ti.

At present, there are neither constitutive laws for strengthening developed for MPEAs specifically - nor any strengthening or deformation mechanisms that are general enough to account for the complexity of microstructures observed in MPEAs. This extends to aspects as simple as identifying if the Hall-Petch relationship is applicable to classes of MPEAs.

Setting processing and synthesis aside, and focusing on corrosion of MPEAs, the selection of elements to form protective oxides has not yet been mastered. Besides ascribing the well-known metal oxides such, as $\mathrm{Al}_{2} \mathrm{O}_{3}, \mathrm{TiO}_{2}, \mathrm{Cr}_{2} \mathrm{O}_{3}$ or alternatively a complex oxide, it is (at present) unknown what creates the 'special properties' observed for MPEAs, and confers good corrosion resistance. For example, questions such as: is it a binary oxide with special properties or phase-separated oxides? Beneficial dopants may be envisioned, but at the same time the variety of oxidation states in complex oxides containing many cation types should increase ionic and electronic defects - which could be detrimental. The so-called 'oxide by design' paradigm has not been established and oxides are largely based on environmental exposures, followed by 'look-and-see'.

The vast majority of MPEAs studied to date have a high density, in other words, they are heavier than most steels (steels possessing a density in the close range of $\sim 8.0 \mathrm{~g} / \mathrm{cm}^{3}$ ). As a consequence, lighter- and lower-density MPEAs represent an area of research endeavour less studied. Furthermore, low alloy cost is also of benefit, particularly from an industrial perspective, as this will influence the uptake of MPEAs whereby cost must be justified by the gain in properties.

The relatively 'recent' advent of MPEAs as materials being researched in the corrosion community means that there is a lack of data regarding their performance in a variety of environments, and besides the usually studied electrolytes such as $\mathrm{NaCl}, \mathrm{HCl}$ and $\mathrm{H}_{2} \mathrm{SO}_{4}$, reports are rare. In addition, long-term performance has not been evaluated in a variety of natural environments. Whilst this applies to all properties, the long-term atmospheric exposure, extended immersion in corrosive electrolytes, or long-term exposure at elevated temperatures, remain essentially unstudied. The challenges in the collection of such data are impacted by several factors, such as: (i) MPEA specimens are typically not large enough to permit accelerated exposure tests such as salt-spray testing; (ii) long-term atmospheric exposure testing requires specialist sites that are usually operated and maintained by industrial companies, albeit with some exceptions. At present, such industrial companies (such as steel and aluminium producers) do not routinely produce MPEAs-and therefore no such data are being generated (and if it is, it is not public domain).

The classifications in Fig. 1 capture many trillions of alloy combinations. Furthermore, the combinations may include billions of alloys, with no overlap in elements with one another. As such, the rudimentary (albeit inclusive) classification of MPEAs is likely to very rapidly be superseded, by simply, the word 'alloys'. Undoubtedly, if critical advances in the field are to occur, a 
deviation from branding that includes HEAs will likely be necessary. The proliferation of works in the area is already making rationalisation of information untenable, since for example, the corrosion mechanism of the alloy AITiCrV ${ }^{89}$ is very much unrelated to the mechanism for $\mathrm{Ni}_{38} \mathrm{Cr}_{21} \mathrm{Fe}_{20} \mathrm{Ru}_{13} \mathrm{Mo}_{6} \mathrm{~W}_{2}{ }^{55}$, and vastly different to the mechanism for AlFeMnSi ${ }^{90}$. They are, for all intents and purposes, different alloy classes.

From the perspective of corrosion science, models of passivity and attendant thermodynamics have notionally been developed for pure metals and simple alloys-that while principally dictated by incongruent dissolution are guided by simple rules of thumb,

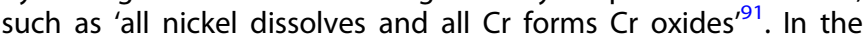
case of MPEAs, one may go as far as making the generalisation that all MPEAs (and inclusive of HEAs and CCAs) undergo incongruent dissolution to various extents. As a consequence, rationalisation of their passivity, their repassivation, and their longterm performance, all require focused research. In addition to phase-separated or complex oxides, there is likely a complicated altered layer underneath the oxide including void formation by both vacancy injection and Kirkendall voiding.

\section{WHAT ARE WE HOPING TO DETERMINE AND HOW?}

The vast possibilities for alloy research, production and then testing, are daunting. As a consequence, attention has rightly been placed on both high throughput alloy design, and the utilisation of machine learning for targeted MPEA systems ${ }^{22,92,93}$. Downselection of systems to study permits tangible sciencebased learning outcomes, and also, are tenable on the basis that there are now (in contrast to alloy development in the early twentieth century) a number of high-throughput methodologies for both alloy production and characterisation ${ }^{94}$. A designdirected approach is also useful for targeted MPEA research. For example, whilst work is now emerging on many HEA systems emerging from these programmes is a need to address unmet needs in metallic materials, including lightweight MPEAs, and lower-density refractory alloys.

There exists a large number of degrees of freedom to optimise MPEAs and their oxides. With certain prerequisites, such as an ability to form a solid solution, alloying elements may be tailored for specific functions such as to limit $\mathrm{Cl}^{-}$adsorption ${ }^{95}$ or sequester cation vacancies, or to alter transport mechanisms prevalent in oxides through the use of so-called trapping agents. The already appreciated complexity of MPEA surface oxides (as noted in the aforementioned studies employing methods including AESEC, 3D-APT and XPS) has frustrated the ability to execute rational thermodynamic calculations-, including CALPHAD methods-, for understanding corrosion or oxidation of MPEAs to date.

There is a precedent for the complexity of passivation layers from multicomponent systems ${ }^{96}$ and thus for a refractory alloy (RMPEAs) with desired mechanical properties, complex passivation behaviour is able to be realised-perhaps addressing short comings to the present limitations in, for example, $\mathrm{Ni}$ based superalloys. The wide compositional space of MPEAs and their resulting microstructures yields a wealth of opportunity for improved mechanical properties ${ }^{68}$. For example, lattice distortion due to atomic disorder can contribute to high strength and ductility ${ }^{97}$. In addition to complex local order strengthening effects ${ }^{98}$, a combination of strengthening secondary phases has been shown to be successful in MPEAs ${ }^{99}$ and extended to RMPEAs to enable a combination of strength and ductility. It is critical that the materials community develop the ability to design MPEAs (and therein, HEAs) like they presently do for high strength, low-alloy steels ${ }^{100}$. This is because such alloys possess tunability at the phase, precipitate, and microstructural level.
Unlike most previous examples of new alloy development and transition into industrial use, the development of MPEAs has a different context-with the vast majority of research and testing being carried out in smaller laboratories and non-industrial researchers. As a consequence, there is (at present) very little industrial testing or industrial alignment of MPEA research. Determination of the potential industry on-ramps and off-ramps for MPEAs is becoming crucial, along with the performance of MPEAs at scale (in size) and indeed, subject to long-term standardised testing. This will require both partnerships with endusers, and most likely with the (ultimate) producers of such alloys.

\section{OPPORTUNITIES AND CHALLENGES}

The compositional variations that are tolerated (and celebrated) in many classes of MPEAs more broadly, permit an ability to recycle metal waste streams very efficiently (i.e. many waste metals or alloys can be used, or designed to be useful).

There are examples of unique alloys emerging, such as the socalled high entropy brasses, as developed by Laws et al. ${ }^{101}$. These alloys have been demonstrated to be readily capable of scaling-up (in size) and readily castable by conventional practices ${ }^{102}$ - placing them in a category of being essentially 'industry ready'. The imminent challenge for MPEAs is their utilisation in speciality or consumer products, including the universal alloy designation of specific compositions and their production with reproducibility in an industrial setting. The field has yet to see a pivot from any major alloy supplier in the world, towards MPEAs; suggesting that an opportunity remains for scaling MPEA production.

Following the point above, the ability to produce MPEAs directing in net-shape by exploiting emerging additive manufacturing technologies has also emerged as a potential production route ${ }^{103}$. The rapid cooling rates in laser-based additive manufacturing methods have resulted in the successful production of a number of MPEAs, including $\mathrm{CoCrFeNi}{ }^{104}, \mathrm{CoCrFe}-$ $\mathrm{NiMn}^{105}$ and MoNbTaW ${ }^{106}$. The corresponding corrosion performance of MPEAs prepared by additive manufacturing is essentially unexplored. However, it is anticipated that defects which accompany the various additive manufacturing technologies, previously outlined by Sander et al. ${ }^{107}$ in the context of corrosion, will all be relevant.

Of the many works and reviews surveyed for this perspective, there is little doubt that MPEAs and associated research is contributing towards ushering in a new era in metallurgy. There are several ways to assess this, but one poignant statement is by Gorsse et al., is that research into MPEAs demands an 'efficient exploration of hyper-dimensional design space ${ }^{\prime 15}$. The present perspective has sought to focus on aspects of MPEAs through the lens of corrosion and durability-but that lens is not decoupled from other properties-such that MPEAs represent an opportunity (perhaps for the first time, in a concerted effort) to include corrosion resistance as a critical design variable amongst a range of critical properties instead of the usual paradigm where primary and secondary properties are investigated in series. It is acknowledged that this concise perspective is unable to be truly comprehensive owing to the emerging breadth of the field, however the many exceptional works to date (and apologetically, the many exceptional works that are un-cited herein) have provided enough insight and firm evidence - that there is much promise in MPEAs with respect to high corrosion resistance. Furthermore, research into MPEAs more broadly has demonstrated movement at the frontiers of understanding metallic structural materials.

\section{DATA AVAILABILITY}

The data in Figs. 2 and 3 are publicly available on Web of Science ${ }^{\mathrm{TM}}$. 
Received: 1 October 2020; Accepted: 12 March 2021; Published online: 07 April 2021

\section{REFERENCES}

1. Shen, H. et al. A novel TiZrHfMoNb high-entropy alloy for solar thermal energy storage. Nanomaterials 9, 248 (2019).

2. Guo, H. X. et al. A novel multilayer high temperature colored solar absorber coating based on high-entropy alloy MoNbHfZrTi: optimized preparation and chromaticity investigation. Sol. Energy Mater. Sol. Cells 209, 110444 (2020).

3. Xiang, C. et al. Corrosion behavior of several high-entropy alloys in high temperature high pressure water. J. Chin. Soc. Corros. Prot. 36, 107-112 (2016).

4. Juan, C. C. et al. Enhanced mechanical properties of HfMoTaTiZr and HfMoNbTaTiZr refractory high-entropy alloys. Intermetallics 62, 76-83 (2015).

5. Sheikh, S. et al. Alloy design for intrinsically ductile refractory high-entropy alloys. J. Appl. Phys. 120, 164902 (2016).

6. Yeh, J. W. et al. Nanostructured high-entropy alloys with multiple principal elements: novel alloy design concepts and outcomes. Adv. Eng. Mater. 6, 299-303 (2004).

7. Tsai, M. H. \& Yeh, J. W. High-entropy alloys: a critical review. Mater. Res. Lett. 2, 107-123 (2014).

8. Murty, B. S., Yeh, J. W. \& Ranganathan, S. High-Entropy Alloys (Elsevier, 2014).

9. Tsai, K. Y., Tsai, M. H. \& Yeh, J. W. Sluggish diffusion in Co-Cr-Fe-Mn-Ni highentropy alloys. Acta Mater. 61, 4887-4897 (2013).

10. Senkov, O. N., Scott, J. M., Senkova, S. V., Miracle, D. B. \& Woodward, C. F. Microstructure and room temperature properties of a high-entropy TaNbHfZrTi alloy. J. Alloy. Compd. 509, 6043-6048 (2011).

11. Youssef, K. M., Zaddach, A. J., Niu, C., Irving, D. L. \& Koch, C. C. A novel lowdensity, high-hardness, high-entropy alloy with close-packed single-phase nanocrystalline structures. Mater. Res. Lett. 3, 95-99 (2014).

12. Zhang, Y. et al. Microstructures and properties of high-entropy alloys. Prog. Mater. Sci. 61, 1-93 (2014).

13. George, E. P., Raabe, D. \& Ritchie, R. O. High-entropy alloys. Nat. Rev. Mater. 4, 515-534 (2019).

14. Yeh, J. W. Alloy design strategies and future trends in high-entropy alloys. JOM 65, 1759-1771 (2013).

15. Gorsse, S., Couzinié, J. P. \& Miracle, D. B. From high-entropy alloys to complex concentrated alloys. C. R. Phys. 19, 721-736 (2018).

16. Qiu, Y. et al. A lightweight single-phase AlTiVCr compositionally complex alloy. Acta Mater. 123, 115-124 (2017).

17. Dasari, S. et al. Engineering transformation pathways in an $\mathrm{Al}_{0.3} \mathrm{CoFeNi}$ complex concentrated alloy leads to excellent strength-ductility combination. Mater. Res. Lett. 8, 399-407 (2020).

18. Butler, T. M., Chaput, K. J., Dietrich, J. R. \& Senkov, O. N. High temperature oxidation behaviors of equimolar $\mathrm{NbTiZrV}$ and $\mathrm{NbTiZrCr}$ refractory complex concentrated alloys (RCCAs). J. Alloy. Compd. 729, 1004-1019 (2017).

19. Charpagne, M. A. et al. Design of Nickel-Cobalt-Ruthenium multi-principal element alloys. Acta Mater. 194, 224-235 (2020).

20. Chai, W., Lu, T. \& Pan, Y. Corrosion behaviors of $\mathrm{FeCoNiCr}_{x}(x=0,0.5,1.0)$ multiprincipal element alloys: role of $\mathrm{Cr}$-induced segregation. Intermetallics 116, 106654 (2020).

21. Gerard, A. Y. et al. Aqueous passivation of multi-principal element alloy $\mathrm{Ni}_{38} \mathrm{Fe}_{20} \mathrm{Cr}_{22} \mathrm{Mn}_{10} \mathrm{Co}_{10}$ : unexpected high $\mathrm{Cr}$ enrichment within the passive film. Acta Mater. 198, 121-133 (2020).

22. Frankel, G. S., Vienna, J. \& Lian, J. WastePD, an innovative center on materials degradation. npj Mater. Degrad. 1, 5 (2017).

23. George, E. P., Curtin, W. A. \& Tasan, C. C. High entropy alloys: a focused review of mechanical properties and deformation mechanisms. Acta Mater. 188, 435-474 (2020).

24. Otto, F. et al. Decomposition of the single-phase high-entropy alloy CrMnFeCoNi after prolonged anneals at intermediate temperatures. Acta Mater. 112, 40-52 (2016).

25. Soni, $\mathrm{V}$. et al. Phase inversion in a two-phase, $\mathrm{BCC}+\mathrm{B} 2$, refractory high entropy alloy. Acta Mater. 185, 89-97 (2020).

26. Manzoni, A. M. et al. Evolution of $\gamma / \gamma^{\prime}$ phases, their misfit and volume fractions in $\mathrm{Al}_{10} \mathrm{CO}_{25} \mathrm{Cr}_{8} \mathrm{Fe}_{15} \mathrm{Ni}_{36} \mathrm{Ti}_{6}$ compositionally complex alloy. Mater. Charact. 154, 363-376 (2019).

27. Gwalani, B. et al. Stability of ordered L12 and B2 precipitates in face centered cubic based high entropy alloys- $\mathrm{Al}_{0.3} \mathrm{CoFeCrNi}$ and $\mathrm{Al}_{0.3} \mathrm{CuFeCrNi}{ }_{2}$. Scr. Mater. 123, 130-134 (2016).

28. Anber, E. A. et al. Insight into the kinetic stabilization of $\mathrm{Al}_{0.3} \mathrm{CoCrFeNi}$ highentropy alloys. Materialia 14, 100872 (2020).
29. Tsai, M. H. et al. Significant hardening due to the formation of a sigma phase matrix in a high entropy alloy. Intermetallics 33, 81-86 (2013).

30. Foley, D. L. et al. Simultaneous twinning and microband formation under dynamic compression in a high entropy alloy with a complex energetic landscape. Acta Mater. 200, 1-11 (2020).

31. Ding, J., Yu, Q., Asta, M. \& Ritchie, R. O. Tunable stacking fault energies by tailoring local chemical order in $\mathrm{CrCoNi}$ medium-entropy alloys. Proc. Natl Acad. Sci. USA 115, 8919-8924 (2018).

32. Li, Q. J., Sheng, H. \& Ma, E. Strengthening in multi-principal element alloys with local-chemical-order roughened dislocation pathways. Nat. Commun. 10, 3563 (2019).

33. Antillon, E., Woodward, C., Rao, S. I., Akdim, B. \& Parthasarathy, T. A. Chemical short range order strengthening in a model FCC high entropy alloy. Acta Mater. 190, 29-42 (2020).

34. Vaidya, M., Guruvidyathri, K. \& Murty, B. S. Phase formation and thermal stability of $\mathrm{CoCrFeNi}$ and $\mathrm{CoCrFeMnNi}$ equiatomic high entropy alloys. J. Alloy. Compd. 774, 856-864 (2019).

35. Jiang, H. et al. Direct solidification of bulk ultrafine-microstructure eutectic highentropy alloys with outstanding thermal stability. Scr. Mater. 165, 145-149 (2019).

36. Han, Z. D. et al. Microstructures and mechanical properties of $\mathrm{Ti}_{x} \mathrm{NbMoTaW}$ refractory high-entropy alloys. Mater. Sci. Eng. A 712, 380-385 (2018).

37. Ahmad, A. S. et al. Structural stability of high entropy alloys under pressure and temperature. J. Appl. Phys. 121, 235901 (2017).

38. Chen, Y. Y., Duval, T., Hung, U. D., Yeh, J. W. \& Shih, H. C. Microstructure and electrochemical properties of high entropy alloys-a comparison with type-304 stainless steel. Corros. Sci. 47, 2257-2279 (2005).

39. Qiu, Y., Gibson, M. A., Fraser, H. L. \& Birbilis, N. Corrosion characteristics of high entropy alloys (HEAs). Mater. Sci. Technol. 31, 1235-1243 (2015).

40. Qiu, Y., Thomas, S., Gibson, M. A., Fraser, H. L. \& Birbilis, N. Corrosion of high entropy alloys. npj Mater. Degrad. 1, 15 (2017).

41. Shi, Y., Yang, B. \& Liaw, P. K. Corrosion-resistant high-entropy alloys: a review. Metals 7, 43 (2017).

42. Scully, J. R. et al. Controlling the corrosion resistance of multi-principal element alloys. Scr. Mater. 188, 96-101 (2020).

43. Huang, L.-F. \& Rondinelli, J. M. Reliable electrochemical phase diagrams of magnetic transition metals and related compounds from high-throughput ab initio calculations. npj Mater. Degrad. 3, 26 (2019).

44. Shi, Y. et al. Corrosion of $\mathrm{Al}_{\mathrm{x}} \mathrm{CoCrFeNi}$ high-entropy alloys: $\mathrm{Al}$-content and potential scan-rate dependent pitting behavior. Corros. Sci. 119, 33-45 (2017).

45. Luo, H., Li, Z., Mingers, A. M. \& Raabe, D. Corrosion behavior of an equiatomic CoCrFeMnNi high-entropy alloy compared with 304 stainless steel in sulfuric acid solution. Corros. Sci. 134, 131-139 (2018).

46. Jayaraj, J., Thinaharan, C., Ningshen, S., Mallika, C. \& Kamachi Mudali, U. Corrosion behavior and surface film characterization of TaNbHfZrTi high entropy alloy in aggressive nitric acid medium. Intermetallics 89, 123-132 (2017).

47. Shuang, S., Ding, Z. Y., Chung, D., Shi, S. Q. \& Yang, Y. Corrosion resistant nanostructured eutectic high entropy alloy. Corros. Sci. 164, 108315 (2020).

48. Chou, Y. L., Wang, Y. C., Yeh, J. W. \& Shih, H. C. Pitting corrosion of the highentropy alloy $\mathrm{Co}_{1.5} \mathrm{CrFeNi}_{1.5} \mathrm{Ti}_{0.5} \mathrm{Mo}_{0.1}$ in chloride-containing sulphate solutions. Corros. Sci. 52, 3481-3491 (2010).

49. Hasannaeimi, V., Ayyagari, A. V., Muskeri, S., Salloom, R. \& Mukherjee, S. Surface degradation mechanisms in an eutectic high entropy alloy at microstructural length-scales and correlation with phase-specific work function. npj Mater. Degrad. 3, 16 (2019).

50. Ayyagari, A. V., Gwalani, B., Muskeri, S., Mukherjee, S. \& Banerjee, R. Surface degradation mechanisms in precipitation-hardened high-entropy alloys. npj Mater. Degrad. 2, 33 (2018).

51. Gerard, A. Y., Lutton, K., Lucente, A., Frankel, G. S. \& Scully, J. R. Progress in understanding the origins of excellent corrosion resistance in metallic alloys: from binary polycrystalline alloys to metallic glasses and high entropy alloys. Corrosion 76, 485-499 (2020).

52. Wang, L. et al. Study of the surface oxides and corrosion behaviour of an equiatomic CoCrFeMnNi high entropy alloy by XPS and ToF-SIMS. Corros. Sci. 167, 108507 (2020).

53. Qiu, Y. et al. Microstructural evolution, electrochemical and corrosion properties of $\mathrm{Al}_{x} \mathrm{CoCrFeNiTi}$, high entropy alloys. Mater. Des. 170, 107698 (2019).

54. $\mathrm{Yu}, \mathrm{X}$. X. et al. Nonequilibrium solute capture in passivating oxide films. Phys. Rev. Lett. 121, 145701 (2018).

55. Quiambao, K. F. et al. Passivation of a corrosion resistant high entropy alloy in non-oxidizing sulfate solutions. Acta Mater. 164, 362-376 (2019).

56. Bagus, P. S., Ilton, E. S. \& Nelin, C. J. The interpretation of XPS spectra: Insights into materials properties. Surf. Sci. Rep. 68, 273-304 (2013). 
57. Biesinger, M. C., Lau, L. W. M., Gerson, A. R. \& Smart, R. S. C. Resolving surface chemical states in XPS analysis of first row transition metals, oxides and hydroxides: Sc, Ti, V, Cu and Zn. Appl. Surf. Sci. 257, 887-898 (2010).

58. Biesinger, M. C. et al. Resolving surface chemical states in XPS analysis of first row transition metals, oxides and hydroxides: $\mathrm{Cr}, \mathrm{Mn}, \mathrm{Fe}, \mathrm{Co}$ and $\mathrm{Ni}$. Appl. Surf. Sci. 257, 2717-2730 (2011).

59. Qiu, Y. et al. Real-time dissolution of a compositionally complex alloy using inline ICP and correlation with XPS. npj Mater. Degrad. 4, 1-6 (2020).

60. Li, X. et al. Communication-dissolution and passivation of a Ni-Cr-Fe-Ru-Mo-W high entropy alloy by elementally resolved electrochemistry. J. Eectrochem. Soc. 167, 061505 (2020)

61. Choudhary, S., Qiu, Y., Thomas, S. \& Birbilis, N. Element-resolved electrochemical analysis of transpassive dissolution and repassivation behavior of the multiprincipal element alloy AITiVCr. Electrochim. Acta 362, 137104 (2020).

62. Ogle, K. \& Weber, S. Anodic dissolution of 304 stainless steel using atomic emission spectroelectrochemistry. J. Eectrochem. Soc. 147, 1770-1780 (2000).

63. Ogle, K. Atomic emission spectroelectrochemistry: real time rate measurements of dissolution, corrosion and passivation. Corrosion 75, 1398-1419 (2019).

64. Taylor, C. D., Lu, P., Saal, J., Frankel, G. S. \& Scully, J. R. Integrated computational materials engineering of corrosion resistant alloys. npj Mater. Degrad. 2, 6 (2018).

65. Zhang, G. et al. High entropy alloy as a highly active and stable electrocatalyst for hydrogen evolution reaction. Electrochim. Acta 279, 19-23 (2018).

66. Wang, Y., Zhang, M., Jin, J., Gong, P. \& Wang, X. Oxidation behavior of $\mathrm{CoCr}$ FeMnNi high entropy alloy after plastic deformation. Corros. Sci. 163, 108285 (2020).

67. Butler, T. M. \& Weaver, M. L. Oxidation behavior of arc melted AlCoCrFeNi multicomponent high-entropy alloys. J. Alloy. Compd. 674, 229-244 (2016).

68. Senkov, O. N., Wilks, G. B., Scott, J. M. \& Miracle, D. B. Mechanical properties of $\mathrm{Nb}_{25} \mathrm{Mo}_{25} \mathrm{Ta}_{25} \mathrm{~W}_{25}$ and $\mathrm{V}_{20} \mathrm{Nb}_{20} \mathrm{Mo}_{20} \mathrm{Ta}_{20} \mathrm{~W}_{20}$ refractory high entropy alloys. Intermetallics 19, 698-706 (2011)

69. Liu, C. M., Wang, H. M., Zhang, S. Q., Tang, H. B. \& Zhang, A. L. Microstructure and oxidation behavior of new refractory high entropy alloys. J. Alloy. Compd. 583, 162-169 (2014).

70. Müller, F. et al. On the oxidation mechanism of refractory high entropy alloys. Corros. Sci. 159, 108161 (2019).

71. Ikeuchi, D. et al. Cr-Mo-V-W: a new refractory and transition metal high-entropy alloy system. Scr. Mater. 158, 141-145 (2019).

72. Gorr, B. et al. Phase equilibria, microstructure, and high temperature oxidation resistance of novel refractory high-entropy alloys. J. Alloy. Compd. 624, 270-278 (2015).

73. Osei-Agyemang, E. \& Balasubramanian, G. Surface oxidation mechanism of a refractory high-entropy alloy. npj Mater. Degrad. 3, 20 (2019).

74. Dąbrowa, J. et al. Influence of $\mathrm{Cu}$ content on high temperature oxidation behavior of $\mathrm{AlCoCrCu}$ FeNi high entropy alloys $(x=0 ; 0.5 ; 1)$. Intermetallics 84 , 52-61 (2017).

75. Esmaily, $\mathrm{M}$. et al. High-temperature oxidation behaviour of $\mathrm{Al}_{x} \mathrm{FeCrCoNi}$ and AlTiVCr compositionally complex alloys. npj Mater. Degrad. 4, 25 (2020).

76. Chen, P. Y. et al. Fatigue behavior of high-entropy alloys: a review. Sci. China Technol. Sci. 61, 168-178 (2018).

77. Hemphill, M. A. et al. Fatigue behavior of $\mathrm{Al}_{0.5} \mathrm{CoCrCuFeNi}$ high entropy alloys. Acta Mater. 60, 5723-5734 (2012).

78. Chuang, M. H., Tsai, M. H., Wang, W. R., Lin, S. J. \& Yeh, J. W. Microstructure and wear behavior of $\mathrm{Al}_{\mathrm{x}} \mathrm{Co}_{1.5} \mathrm{CrFeNi}_{1.5}$ Tiy high-entropy alloys. Acta Mater. 59, 6308-6317 (2011)

79. Liu, K. et al. Effect of nano-sized precipitates on the fatigue property of a lamellar structured high entropy alloy. Mater. Sci. Eng. A 760, 225-230 (2019).

80. Joseph, J. et al. The sliding wear behaviour of $\mathrm{CoCrFeMnNi}$ and $\mathrm{AlxCoCrFeNi}$ high entropy alloys at elevated temperatures. Wear 428-429, 32-44 (2019).

81. Wu, J. M. et al. Adhesive wear behavior of AlxCoCrCuFeNi high-entropy alloys as a function of aluminum content. Wear 261, 513-519 (2006).

82. Li, W., Chen, S. \& Liaw, P. K. Discovery and design of fatigue-resistant highentropy alloys. Scr. Mater. 187, 68-75 (2020).

83. Vaidya, M., Muralikrishna, G. M. \& Murty, B. S. High-entropy alloys by mechanical alloying: a review. J. Mater. Res. 34, 664-686 (2019).

84. Chen, S., Tong, Y. \& Liaw, P. K. Additive manufacturing of high-entropy alloys: a review. Entropy 20, 937 (2018).

85. Shun, T. T., Hung, C. H. \& Lee, C. F. The effects of secondary elemental Mo or Ti addition in $\mathrm{Al}_{0.3} \mathrm{CoCrFeNi}$ high-entropy alloy on age hardening at $700^{\circ} \mathrm{C}$. J. Alloy. Compd. 495, 55-58 (2010)

86. He, J. Y. et al. A precipitation-hardened high-entropy alloy with outstanding tensile properties. Acta Mater. 102, 187-196 (2016).

87. Gwalani, B. et al. Modifying transformation pathways in high entropy alloys or complex concentrated alloys via thermo-mechanical processing. Acta Mater. 153, 169-185 (2018)
88. Laplanche, G. et al. Phase stability and kinetics of $\sigma$-phase precipitation in CrMnFeCoNi high-entropy alloys. Acta Mater. 161, 338-351 (2018).

89. Qiu, Y. et al. Microstructure and corrosion properties of the low-density singlephase compositionally complex alloy AITiVCr. Corros. Sci. 133, 386-396 (2018).

90. Choudhary, S. et al. On the dynamic passivity and corrosion resistance of a low cost and low density multi-principal-element alloy produced via commodity metals. Electrochem. Commun. 125, 106989 (2021).

91. Li, X. \& Ogle, K. The passivation of Ni-Cr-Mo alloys: time resolved enrichment and dissolution of $\mathrm{Cr}$ and Mo during passive-active cycles. J. Electrochem. Soc. 166, C3179-C3185 (2019).

92. Huang, W., Martin, P. \& Zhuang, H. L. Machine-learning phase prediction of highentropy alloys. Acta Mater. 169, 225-236 (2019).

93. Wen, $C$. et al. Machine learning assisted design of high entropy alloys with desired property. Acta Mater. 170, 109-117 (2019).

94. Scully, J. R. \& Balachandran, P. V. Future frontiers in corrosion science and engineering, part III: the next "Leap Ahead" in corrosion control may be enabled by data analytics and artificial intelligence. Corrosion 75, 1395-1397 (2019).

95. Ke, H. \& Taylor, C. D. First-principles modeling of the repassivation of corrosion resistant alloys: part I. $\mathrm{O}$ and $\mathrm{Cl}$ adsorption energy. J. Electrochem. Soc. 167, 111502 (2020).

96. Nijdam, T. J., Kwakernaak, C. \& Sloof, W. G. The effects of alloy microstructure refinement on the short-term thermal oxidation of NiCoCrAlY alloys. Metall. Mater. Trans. A 37A, 683-693 (2006)

97. Lee, $C$. et al. Lattice distortion in a strong and ductile refractory high-entropy alloy. Acta Mater. 160, 158-172 (2018).

98. Li, X. G., Chen, C., Zheng, H., Zuo, Y. \& Ong, S. P. Complex strengthening mechanisms in the NbMoTaW multi-principal element alloy. npj Comput. Mater. 6, 70 (2020).

99. Liang, Y. J. et al. High-content ductile coherent nanoprecipitates achieve ultrastrong high-entropy alloys. Nat. Commun. 9, 4063 (2018).

100. Isasti, N., Jorge-Badiola, D., Taheri, M. L. \& Uranga, P. Microstructural features controlling mechanical properties in Nb-Mo microalloyed steels. Part I: yield strength. Metall. Mater. Trans. A 45A, 4960-4971 (2014).

101. Laws, K. J. et al. High entropy brasses and bronzes-Microstructure, phase evolution and properties. J. Alloy. Compd. 650, 949-961 (2015).

102. Nagase, T., Shibata, A., Matsumuro, M., Takemura, M. \& Semboshi, S. Alloy design and fabrication of ingots in $\mathrm{Cu}-\mathrm{Zn}-\mathrm{Mn}-\mathrm{Ni}-\mathrm{Sn}$ high-entropy and $\mathrm{Cu}-\mathrm{Zn}-\mathrm{Mn}-\mathrm{Ni}$ medium-entropy brasses. Mater. Des. 181, 107900 (2019).

103. Torralba, J. M. \& Campos, M. High entropy alloys manufactured by additive manufacturing. Metals 10, 639 (2020)

104. Brif, Y., Thomas, M. \& Todd, I. The use of high-entropy alloys in additive manufacturing. Scr. Mater. 99, 93-96 (2015).

105. Tong, Z. et al. Laser additive manufacturing of FeCrCoMnNi high-entropy alloy: effect of heat treatment on microstructure, residual stress and mechanical property. J. Alloy. Compd. 785, 1144-1159 (2019).

106. Moorehead, M. et al. High-throughput synthesis of Mo-Nb-Ta-W high-entropy alloys via additive manufacturing. Mater. Des. 187, 108358 (2020).

107. Sander, G. et al. Corrosion of additively manufactured alloys: a review. Corrosion 74, 1318-1350 (2018)

\section{ACKNOWLEDGEMENTS}

M.L.T. and J.R.S. gratefully acknowledge funding from the Office of Naval Research through the Multidisciplinary University Research Initiative (MURI) programme (Award \#: N00014-20-1-2368).

\section{AUTHOR CONTRIBUTIONS}

All authors contributed to the conception, writing, and editing of the article.

\section{COMPETING INTERESTS}

The authors declare no competing interests.

\section{ADDITIONAL INFORMATION}

Correspondence and requests for materials should be addressed to N.B. or S.C.

Reprints and permission information is available at http://www.nature.com/ reprints

Publisher's note Springer Nature remains neutral with regard to jurisdictional claims in published maps and institutional affiliations. 
Attribution 4.0 International License, which permits use, sharing, adaptation, distribution and reproduction in any medium or format, as long as you give appropriate credit to the original author(s) and the source, provide a link to the Creative Commons license, and indicate if changes were made. The images or other third party material in this article are included in the article's Creative Commons license, unless indicated otherwise in a credit line to the material. If material is not included in the article's Creative Commons license and your intended use is not permitted by statutory regulation or exceeds the permitted use, you will need to obtain permission directly from the copyright holder. To view a copy of this license, visit http://creativecommons. org/licenses/by/4.0/.

(c) The Author(s) 2021 